\title{
Physio-pathology of the Internal Anal Sphincter
}

\author{
BERNARD DUHAMEL \\ From le Département de Chirurgie Infantile, Centre Hospitalier de Saint-Denis, 93, France
}

In normal physiological studies, using electrical, manometric, or cinematographic methods, it is practically impossible to separate the role of the internal sphincter from that of the other elements of the functional ensemble forming the anal sphincteric system (Aron and Thouvenot, 1962; Lawson and Nixon, 1967; Schnaufer et al., 1967).

It is only by studying the pathology of the area that it is possible to have an idea of what may be the role of each of the elements of this system in recto-anal continence.

I should like, today, to summarize for you the research which I have for some years been undertaking on the neuro-anatomy and the physiology of the internal anal sphincter (Duhamel, 1967; Duhamel and Pagès, 1968; Pagès, 1967).

\section{Role of Internal Sphincter in Recto-anal Continence}

I shall first outline the reasons which have led me to try to elucidate further the role of the internal sphincter in recto-anal continence.

In 1956, I proposed a new operation for the treatment of Hirschsprung's disease, the retrorectal and trans-anal pull-through of the colon (Duhamel, 1960).

With this operation I hoped to remedy some of the disadvantages of Swenson's recto-sigmoidectomy, in particular by retaining the anterior wall of the aganglionic rectum, to preserve the reflex mechanisms of defaecation, and by lowering down the posterior wall of the normally innervated colon to the ano-cutaneous limit, to suppress the action of the internal sphincter at that point. This sphincter, according to accepted opinion at that time, was always abnormal in Hirschsprung's disease, since non-ganglionic cells have been seen at its level. The occurrence, after recto-sigmoidectomy, of such disturbances as enterocolitis, distension, slowness of the recession of colonic dilatation, and even minor tendencies to recur, justified this point of view.

Received November 25, 1968.

*Simpson Smith Lecture 1968, Institute of Child Health, University of London.
Because of its simplicity, this new operation was immediately adopted by some surgeons and this rapidly permitted an appreciation of its results based on many more observations than my own. These observations have confirmed the safety of the procedure and the complete absence of postoperative troubles or recurrences, apart from a few reports of stenosis of the colono-rectal anastomosis, a secondary complication easily cured by a new enterostomy.

However, as far back as 1959, Grob, Genton and Vontobel, of Zurich, noticed that in some patients whose post-operative condition was otherwise satisfactory, there was 'soiling' of pants, by gases or liquid matter, while voluntary continence was practically perfect. This minor complication was also noticed by Kostia (1962), Sulamaa's assistant at Helsinki. Grob thought that the cause of this soiling was the complete sectioning of the internal anal sphincter, and he suggested that perhaps the internal sphincter was normally not autonomically innervated, and did not therefore come within the sphere of Hirschsprung's disease. He, therefore, proposed to modify the retro-rectal pullthrough by making it above the internal sphincter. This procedure did, indeed, eliminate post-operative soiling completely, but brought with it certain other disadvantages, as we shall see later.

Grob's publications, therefore, drew attention to two points: first, the part played by the internal sphincter in the automatic continence of gases and liquids (when the rest of the sphincteric system was retained), and second, the possible absence of autonomic innervation of the internal sphincter.

\section{Megarectum in Childhood}

I then became more closely interested in this latter point, in studying the megarectum in childhood (Duhamel, 1966).

Bodian, Stephens, and Ward (1949) classified megacolons into three categories:

(1) Congenital megacolon (or Hirschsprung's disease) is a retro-dilatation of the colon above a functionally contracted aganglionic zone, which, though more or less extensive is always from below 
upwards, and, therefore, always (at least partially) affecting the rectum.

(2) Organic megacolon is in reality a dilatation of the rectum above a congenital obstacle (e.g. an ano-rectal malformation not totally imperforate), and either secondary, or acquired as the result of an operation on the anus, particularly the results of pull-through for anal imperforation.

(3) Functional megacolon is diagnosed where no local lesion, either congenital or acquired, can be brought to light.

In both organic and functional megacolon, the dilatation mainly affects the rectum, and it seems better to classify these two latter types of disease as megarectums, rather than as real megacolons. The qualification 'functional' should not be reserved for this latter category of megarectum, since Hirschsprung's disease is the result of functional trouble, too. As for the qualification 'idiopathic', which is also used, it only serves to hide our ignorance, and we shall see that it can but rarely be retained. That is why I prefer to call non-organic megarectums 'recto-anal achalasias'.

The recto-anal achalasia-in the child as in the adult-can be ascribed to dietetic or psychogenic causes, and then responds very well to adequate treatment. But there are many cases where the trouble appears very early in life, at weaning for instance, or in a psychologically stable subject; and others where emotional disturbances are present and yet the condition does not disappear after psychotherapy. In these it is often difficult, particularly when the family is traumatically involved in the situation, to sort out the congenital from the acquired factors in the aetiology of the condition.

A certain number of children presenting with megarectum of this type were submitted to a rectal biopsy using Swenson's procedure (Swenson, Fisher, and MacMahon, 1955), with a view either to finding, or eliminating, a limited degree of Hirschsprung's disease. These biopsies were carried out right on to the rectal wall at about $5 \mathrm{~cm}$. from the anal limit, and always showed the existence of a normal autonomous innervation even when almost all the rectum was dilated.

Recto-sigmoidectomy does not improve these children, while retro-rectal pull-through always cures them. However, it seems to me that this surgical intervention is out of proportion to the gravity of the disease. That is why I have endeavoured to study and treat those recto-anal achalasias which resisted medical and psychotherapeutical treatment, and in which the biopsy of the rectum was normal, by myotomy of the internal sphincter, involving the lower part of the rectal wall.

But before interpreting the detail of sphincterectomy-biopsy, we had to know what was the normal neuro-anatomy of the internal anal sphincter, a problem which, to the best of our knowledge, had not been the subject of thorough research. I therefore asked Professor Roujeau, Head of the Pathology Department of the Saint-Denis Hospital, to undertake a study of the normal innervation of the internal anal sphincter (Alamowitch, Gubler, and Roujeau, 1966).

100 rectums were examined, 48 from deceased premature babies, 21 from stillborn full-term babies, 16 from deceased newborn babies and infants whose deaths were due to various causes, and 15 from adults. The internal sphincter, which is a thickening and prolongation of the internal circular layer of the rectal wall, was always found to be devoid of ganglionic cells. There is, indeed, no Meissner plexus in the submucosa which covers it, and the rare ganglionic cells of the Auerbach intermuscular plexus (found in only 1 in 4) accompany the external longitudinal layer of the rectal wall which sometimes overlaps the upper part of the internal sphincter before losing itself in the direction of the external striated sphincteric plane.

This study shows, therefore, that the internal sphincter itself has no autonomous innervation, unlike the rest of the digestive tube. Even if efferent nerves do exist at the level of this sphincter, there is a rupture of colo-rectal peristalsis at that point.

The operation of partial sphincterectomy-biopsy of the internal sphincter is performed as follows. After dilatation of the anus, a three-armed retractor is installed. The posterior part of the mucocutaneous junction is stretched between two clamps, and incised with a scalpel for a few centimetres; the mucosa of the anal canal and of the lower rectum is separated from the muscular wall with blunt scissors; the internal sphincter is isolated and separated from the external striated sphincter; a muscular strip $-1 \mathrm{~cm}$. wide and 5 or $6 \mathrm{~cm}$. long, is removed with scissors; finally, the muto-cutaneous incision is sutured by a few separate silk stitches, and haemostasis is ensured by introducing a large pad of gauze into the anus

This operation is simple and rapid and has never given rise to complications. It permits the cure of almost all the recto-anal achalasias, since it corresponds to Heller's operation for cardio-oesophageal achalasia, and Ramstedt's operation for hypertrophic stenosis of the pylorus. 
Last, but not least, it permits a valid histological study of the internal sphincter, and the lower rectal wall, below the level at which rectal biopsy is normally carried out.

I have operated in this way on 33 children whom the paediatricians had sent me because they presented idiopathic megacolons which no medical treatment had been able to alleviate. I was surprised to note that the histological structure and innervation of the specimens were seldom both normal.

In 15 cases, the internal sphincter structure was absolutely normal, but no ganglionic cells were found in the lower part of the rectal wall. These were therefore real cases of Hirschsprung's disease, but with an ultra-short aganglionic segment, limited to the recto-anal junction. Similar observations were published by Bentley (1966).

In 14 other cases, the innervation of the lower rectal wall was normal, but the structure of the internal sphincter was abnormal. In certain cases, the smooth muscle was dissociated by sclerosis and intimately mingled with striated muscle fibres; in some cases there was even a complete absence of smooth muscle which had been replaced by striated fibres which were more or less fibrotic.

These histological aspects are the same as may be observed in congenital anal stenosis, or in the biopsy of recto-vulvar fistulas. I, therefore, think it is a question of a minor degree of anorectal malformation, and this appears to be proved by the frequent existence, in these cases, of associated anomalies belonging to the group of 'caudal regression', such as the malformations of the spine or of the genito-urinary apparatus.

These two categories of recto-anal achalasia may thus be reclassified, the one within the scope of Hirschsprung's disease, the other within the scope of organic megacolon.

I only found 4 cases of megarectums which appeared really idiopathic, the internal sphincter being strictly normal and the juxta-sphincteric area being normally innervated. Sphincterectomy brought about a complete cure in 2 of the cases. In the other 2 , there was considerable improvement.

These facts give food for thought.

As a result of this histological study of the rectoanal achalasia, and leaving aside those cases of structural modification which come within the scope of minor congenital ano-rectal malformations, it may be noted that the role of the internal sphincter appears to be of prime importance in the recto-anal sphincteric function, when the external apparatus is normal. First, in the absence of any patent neurological anomaly in the rectal wall, the internal sphincter is susceptible of being the seat of a functional obstacle to normal defaecation, and the resulting megarectum may easily be cured by a simple partial sphincterectomy. Secondly, when a limited ring-shaped aganglionic area of the lower rectal wall exists, its association with a dysfunction of the internal sphincter may bring about serious retention trouble.

\section{Internal Sphincter in Hirschsprung's Disease}

This brings me to the third part of my subjectthat is to say the part that the internal sphincter may play in true Hirschsprung's disease.

While the general physio-pathology of Hirschsprung's disease is now well known, taking into account all the usual forms of the disease, the paediatricians and surgeons who are called upon to observe a large number of cases cannot fail to be impressed by a certain number of contradictions both in the clinical evolution of the disease and in certain inexplicable operational failures, or conversely by the final success of operations which are illogical in relation to the classical physio-pathological concept.

On the evolutionary and clinical planes, if one admits a simple and specific mechanism, it is difficult to accept that it may be independently responsible both for (1) the so-called 'tolerated' Hirschsprung's disease, which culminates in the classical picture of a congenital megacolon, easily cured by a logical operation, even in unskilful hands; and, (2) the serious Hirschsprung's disease in the newborn, which decompensates quickly, and which surgical treatment does not always cure even when the diagnosis and execution of the operation have been beyond reproach.

What is more, one notes that certain relatively widespread forms of aganglionism are sometimes better tolerated than topographically commonplace recto-sigmoid forms and even certain short and ultra short forms.

On the surgical plane, we find the same contradictions. At the beginning of this paper, I said that the Swenson-type recto-sigmoidectomy (Swenson and Bill, 1948), which leaves the 2 or $3 \mathrm{~cm}$. ano-rectal wall which is necessary for the end-to-end anastomosis, usually gives excellent results, but that in certain cases it is accompanied by difficulties when passage of faeces is restarted, e.g. enterocolitis, slowness in the recession of colic-dilatation, and sometimes recurrences even when the aganglionic colon has been fully resected.

On the other hand, the anterior resection carried out by certain paediatric surgeons, such as State 
(1952), in America, and Rehbein and Zimmermann (1960) and Rehbein and Nicolai (1963), in Germany, leaves, in the best cases, 5 to $8 \mathrm{~cm}$. aganglionic rectum in the pelvis, i.e. much more than we can see in the short forms of Hirschsprung's disease which, however, may be of the highest clinical gravity. According to these surgeons, this operation nevertheless gives results comparable to those of recto-sigmoidectomy.

These facts suggest that as well as the absence of real intestinal peristalsis, the achalasia of the internal anal sphincter must play a major role in certain megacolons. Rehbein et al. (1966) and Swenson and Scott (1960) willingly admit this, since they have suggested improving their operational failures by a complementary sphincterotomy. Swenson (1964) even proposed to modify the rectosigmoidectomy by an oblique anastomosis, retaining a part of the anterior rectal wall, and suppressing the greater part of the internal sphincter posteriorly.

The practice of the retro-rectal pull-through has confirmed this hypothesis. As stated earlier, Grob et al. (1959) modified my operation by lowering the colon above the internal anal sphincter, in order to retain the role of automatic continence of that muscle, as concerns gases and liquid matter. The practice of retro-rectal supra-sphincteric pull-through has, however, shown that a new complication might appear which was not observed when the pull-through was carried out at the anocutaneous level; this is the impaction of faeces in the rectal blind pouch. This proves the hypertonicity of the internal sphincter in these cases, since here too sphincterectomy suffices to eliminate these accidents (Pagès, 1967).

For some years now, I have pointed out that, to avoid post-operative soiling, the pull-through should be effected in the middle part of the anal canal, thus eliminating the excess in length and tonicity of the internal sphincter, but retaining a small ring which always suffices to avoid soiling. This technique is extremely easy to carry out if the posterior wall is unwound on the plug which has just effected the retro-rectal cleavage (Duhamel, 1964).

The preponderant role the internal sphincter sometimes plays in Hirschsprung's disease, also discussed by Soper (1967) in America, is confirmed by a recent publication of Lynn (1968), from Rochester, who proposed treating Hirschsprung's disease initially by a longitudinal myectomy of the greater part of the internal sphincter and as long a stretch as possible of the rectal wall. He noticed that even if a long aganglionic segment remained above this myectomy, it was possible to obtain cures in a certain number of cases.

These results contrast with those of rectosigmoid-myotomy from above, described by Weiss, Hollender, and Wagner (1956), which always ended in failure, because it could not involve the internal sphincter (Weiss, Hollender, and Adloff, 1959).

\section{Conclusions}

To wind up this physio-pathological outline, several conclusions may be drawn, which, furthermore, are confirmed by recent work in Germany (Stelzner, 1967), and America (Soper, 1967).

The internal anal sphincter does not have its own autonomous innervation. It therefore does not participate actively either in the mechanism of rectal evacuation, or in that of the function of the voluntary sphincteric apparatus.

Like certain smooth muscles in their normal state and like all smooth muscular fibres in a state of denervation, the internal sphincter is in a state of permanent contraction. This permanent tonicity permits automatic continence of gases and liquid matters when the external sphincter is at rest and even when it is relaxed, as in sleep or under light anaesthesia. The internal sphincter can ensure a certain continence on its own even when there is destruction or paralysis of the striated sphincteric system, as, for example, in sacral agenesis.

Normally, colo-rectal peristalsis, and abdominal pressure, together with voluntary relaxation of the striated sphincteric system, enable the functional obstacle of the internal sphincter to be overcome.

If there is a deficiency of the colo-rectal function as in colonic or rectal inertia, or in cases of minor or atypical faults of autonomic innervation, the normal tonus of the internal sphincter will be sufficient to prevent the evacuation of faeces, and so give the impression that the recto-anal achalasia is idiopathic. A recent symposium of the British Association of Paediatric Surgeons was devoted to these pseudo-Hirschsprung's conditions, and we may, in particular, note the interventions of Nixon (1966), and Pagès and Duhamel (1966).

In certain conditions, the functional obstacle presented by the internal anal sphincter is exaggerated and becomes the cause of pathological troubles, either in the absence of any overlying intestinal lesion (as in a really idiopathic recto-anal achalasia), or in association with a fault in the autonomous innervation of the rectum. This excess of tonus in the internal sphincter explains the paradoxical character of certain immediately serious forms of Hirschsprung's disease, the clinical 
manifestation of limited aganglionism, and the majority of the bad functional results of the various operations for congenital megacolon.

The importance of the internal sphincter in the automatic continence of gases and liquid matter, and its character of a simple smooth muscular ring in a state of permanent tonicity, have led me to conceive a technique for the construction of a smooth artificial sphincter to improve continence after perineal pull-through of the colon for anorectal malformation, and possibly for other reasons.

Since the internal sphincter is anatomically only a thickening of the circular layer of the rectum, it is possible to reproduce this muscular thickening by turning back the muscular wall of the colon, like a cuff, after having cut away the mucosa for a few centimetres. The ring thus made is much thicker and more tonic than one might think. It is attached above at the level of the levators, and is fixed below to the external anal sphincter, and the stripped mucosa, once the excess has been cut away, is sutured to the peri-anal skin.

Up to now, I have only limited experience of this operation, and no results of long duration. But the reconstruction of anal tonus was obtained immediately, even if the striated sphincter was non-existent, and re-establishment of continence appeared satisfactory after several months.

I therefore think that this experimental procedure merits further development and in those cases where good results are confirmed, we would perhaps be able to bring real relief to a large number of patients with anal incontinence, patients to whom the various plastic operations employing a voluntary muscle seldom give total automatic continence.

\section{REFERENCES}

Alamowitch, C., Gubler, J. P., and Roujeau, J. (1966). L'innervation du sphincter lisse de l'anus. Arch. Anat. path., 14, 28. Aron, E., and Thouvenot, J. (1962). Physiologie de la continence anale. Arch. Mal. Appar. dig., 51 (7-8), suppl. 17.

Bentley, J. F. R. (1966). Posterior excisional ano-rectal myotomy in management of chronic faecal accumulation. Arch. Dis. Childh., 41, 144.

Bodian, M., Stephens, F. D., and Ward, B. C. H. (1949). Hirschsprung's disease and idiopathic megacolon. Lancet, 1, 6.

Duhamel, B. (1960). A new operation for the treatment of Hirschsprung's disease. Arch. Dis. Childh., 35, 38.

- (1964). Retrorectal and transanal pull-through procedure for the treatment of Hirschsprung's disease. Dis. Colon Rect., $7,455$.
(1966). Histological investigations into 'idiopathic megacolon'. Arch. Dis. Childh., 41, 150.

(1967). Notions récentes sur la maladie de Hirschsprung. XXIIe Congrès de la Société Intern. de Chir, Vienna, p. 1243.

_, and Pagès, R. (1968). Physiopathologie du sphincter interne de l'anus chez l'enfant. Vie méd., 49, 775.

Grob, M., Genton, N., and Vontobel (1959). Erfahrungen in der operativen Behandlung des Megacolon congenitum und Vorschlag einer neuer Operationstechnic. Zbl. Chir., 8, 1781.

Kostia, J. (1962). Results of surgical treatment in Hirschsprung's disease. Arch. Dis. Childh., 37, 167.

Lawson, J. O. N., and Nixon, H. H. (1967). Anal canal pressures in the diagnosis of Hirschsprung's disease. $\mathcal{F}$. pediat. Surg., 2, 544.

Lynn, H. B. (1968). Personal experience with rectal myectomy in the treatment of selected cases of aganglionic megacolon. Z.Kinderchirurgie., 5, suppl. 98.

Nixon, H. H. (1966). What is Pseudo-Hirschsprung's disease? Arch. Dis. Childh., 41, 147.

Pagès, R. (1967). Fécalome du cul-de-sac rectal après opération de Duhamel. Ann. Chir. infant., 8, 193.

-, and Duhamel, B. (1966). Intrinsic non-propulsive colon. Arch. Dis. Childh., 41, 151.

Rehbein, F., Morger, R., Kundert, J. G., and Meier-Ruge, W. (1966). Surgical problems in congenital megacolon. $\mathcal{F}$.pediat. Surg., 1, 526.

- and Nicolai, I. (1963). Operation der Hirschsprungschen Krankheit. Dtsch. med. Wschr., 88, 1595.

- and Zimmermann, H. von (1960). Results with abdominal resection in Hirschsprung's diease. Arch. Dis. Childh., 35, 29.

Schnaufer, L., Talbert, J. L., Haller, J. A., Reid, N. C. R. W., Tobon, F., and Schuster, M. M. (1967). Differential sphincteric studies in the diagnosis of ano-rectal disorders of childhood. F. pediat. Surg., 2, 538.

Soper, R. T. (1967). Nouvelle intervention pour la maladie de Hirschsprung. Meeting of the Section of American Academy of Pediatrics, Washington.

State, D. (1952). Surgical treatment for idiopathic congenital megacolon. Surg. Gynec. Obstet., 95, 201.

Stelzner, F. (1967). Die rektoanale Kontinenz. Z. Kinderchirurgie., 5, 227.

Swenson, O. (1964). Partial internal sphincterectomy in the treatment of Hirschsprung's disease. Ann. Surg., 160, 540.

_, and Bill, A. H., Jr. (1948). Resection of rectum and rectosigmoid with preservation of the sphincter for benign spastic lesions producing megacolon. Surgery, 24, 212.

_- Fisher, J. H., and MacMahon, H. E. (1955). Rectal biopsy as an aid in the diagnosis of Hirschsprung's disease. New Engl. F. Med., 253, 632.

—, and Scott, J. E. S. (1960). Diarrhea following rectosigmoidectomy for Hirschsprung's disease. Surgery, 48, 419.

Weiss, A. G., Hollender, L., and Adloff, M. (1959). Étude critique des résultats éloignés de la sigmoïdo-rectomyotomie. In 61e Congres Franfais de Chirurgie, p. 172. Presses Univ. de France, Paris.

- , and Wagner, J. P. (1956). Traitement du mégacôlon congénital par la sigmoïdo-recto-myotomie. Arch. Mal. Appar. dig., 45, pt. 2, 49.

Correspondence to Professor Bernard Duhamel, Département de chirurgie infantile, Centre Hospitalier de Saint-Denis, 11, Rue Danielle-Casanova, 93-Saint Denis, France. 